\section{ECONOMICS}

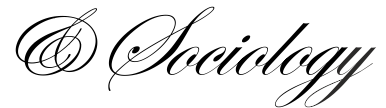

\author{
Mihaela Simionescu \\ PhD, Senior Researcher \\ Institute for Economic Forecasting \\ of the Romanian Academy \\ Bucharest, Romania \\ E-mail:mihaela_mb1@yahoo.com
}

Received: December, 2013

1st Revision: March, 2014

Accepted: April, 2014

DOI: $10.14254 / 2071-$

789X.2014/7-1/5
Mihaela Simionescu, Testing Sigma Convergence Across EU-28, Economics \& Sociology, Vol. 7, No 1, 2014, pp. 48-60. DOI: 10.14254/2071-789X.2014/7$1 / 5$

\title{
TESTING SIGMA CONVERGENCE ACROSS EU-28
}

\begin{abstract}
The main goal of this research is to assess the degree of convergence in European Union- 28 (EU28) during 2000-2012. After a spatial analysis of macroeconomic indicators using maps and graphs that were built in GeoDa, the sigma convergence was tested. For this purpose, variation indicators in the simple and weighted variant for GDP per capita in PPS were utilized, the weights being given by the population weights in each country of the EU-28. The results indicated a decrease in divergence process in 2012 compared to 2000 , but there is still not enough evidence for the closeness of an acceptable degree of convergence. However, there is a low degree of divergence in EU-28 compared to EU-27 in 2012 with respect to 2000. In 2012, the EU-28 populations explained better the GDP compared to the number of employed persons.
\end{abstract}

JEL Classification: C18, C88, Keywords: convergence, sigma convergence, GDP per capita, F2, F15 standard deviation, variance, coefficient of variation.

\section{Introduction}

For measuring the degree of realization for the convergence process one should assess the levels of different indicators that refer to: variability/homogeneity, polarization, concentration, complementarity, entropy. These indicators might confirm or not different aspects of the convergence process. The most known and applied is the sigma convergence measured by variation indicators.

This paper is structured in several parts. After this brief introduction, a short literature review is made, underlying the latest results regarding the convergence assessment. The methodological part consists in the presentation of the statistical indicators used in measuring the variation in GDP/capita. The empirical application supposes the calculation of variation measures for European Union-28. The results put into evidence that during 2000-2012 the convergence criterion was not fulfilled, even if the degree of variability decreased in time. A section dedicated to main conclusions was presented in the end.

\section{Literature}

According to Sala-i-Martin (1996), $\beta$ and $\sigma$ indicators are new tools for measuring the degree of convergence and the speed for getting convergence. $\sigma$ indicator shows the convergence and divergence tendency depending on the value of sample variance. $\beta$ 
parameter shows the speed for accomplish the convergence when it has a negative sign. Mankiw, Romer and Weil (1992) and Islam (1995) introduced in the model control variables like saving rate and population growth, showing that the economies with a low initial income tend to grow faster than the economies with higher income. On the other hand, alternative econometric models were developed by Quah (1996) and Durlauf (1996) to show that the transversal growth model is consistent with the multiple mechanisms of endogenous growth and inconsistent with the convergence. The behavior and evolution of convergence-clubs were deeply analyzed. The conventional theory of convergence and the empirical researches hide the convergence-clubs and the polarization of countries in rich in poor. Some economists like Friendman (1992) and Quah (1996) considered the beta indicator as irrelevant for the real convergence process of the economic growth. There are several forms for this tool utilized in econometric analysis: absolute beta convergence, club convergence and conditional beta convergence. The beta and sigma indicators are related and reciprocal checked. The assumption of diminishing yield of the neo-classical theory states that poor economies tend to grow faster than rich ones. This conclusion has the following implications: the coefficient of variation for GDP/capita slowly decreases and there is an inverse relationship between the rate of economic growth for GDP/capita and the initial level of GDP/capita. However, the Sala-i-Martin (1996) suggested that different relationships may occur between these two types of convergence.

Azomahou, El ouardighi, Nguyen-Van, and Cuong Pham (2011) used a semiparametric partially linear model to evaluate the convergence across EU members, indicating no convergence for high income countries. Beyaert and García-Solanes (2014) evaluated the effect of economic conditions on long-term economic convergence. The GDP/capita convergence is not the same on the business cycle during 1953-2010. Cuaresma, Havettová and Lábaj (2013) evaluated the income convergence dynamics using forecast models for European countries, the future human capital investment being a factor that will generate income convergence.

Palan and Schmiedeberg (2010) tested the structural convergence for Western European countries using unemployment rate data. The divergence is obvious in technologyintensive manufacturing industries. Le Pen (2011) applied the pair-wise approach of convergence proposed by Pesaran (2007) to the output per capita of some European regions.

Crespo-Cuaresma and Fernández-Amador (2013) evaluated the dynamics of the standard deviation for European area business cycles to figure out the convergence patterns. In eighties a relevant business cycle divergence was observed and in nineties a persistent convergence was assessed.

Kutan and Yigit (2009) used a panel data analysis for 8 new members of the European Union and showed that human capital is the most important factor that determined productivity growth during 1995-2006. Monfort, Cuestas, and Ordóñez (2013) used a cluster analysis, observing two convergence clubs in EU-14 countries, the Eastern European members being also divided in two groups.

Iancu (2009) used the sigma convergence to measure the evolution of real convergence process between the EU countries on three groups: EU-25, EU-15 and EU-10, the coefficient of variation indicating a divergence growth of the economies during 19952006. Mihuţ and Luţaş (2013) measured the sigma convergences across the new members of the European Union.

\section{Methodology}

The methodological approach regarding the convergence is based on the scientific contribution brought by Solow. This neoclassical model had a huge impact on the new models 
in order to diminish the gap between the real conditions of the economy and the different versions. The economic growth could be supported by investments that generate positive externalities associated with the development of human capital. In the new approach of convergence, the human and physical capital together with the technologic process contributed to the convergence realization. On the other hand, the econometric methods are more used in testing the assumptions of the models.

The variation is measured for more elements like regions and countries using simple indicators (the deviation, the range) and synthetic indicators (average linear deviation, variance, standard deviation, and coefficient of variation). The synthetic indicators express the distance between a variable values for each of the element and the average level. The convergence stage at a certain moment is assessed using an indicator of variation that shows rather the opposite aspect of convergence, because it expresses in a numerical form how far the elements of the entire are from the central level towards the values of the indicator converges.

In a dynamic analysis the variation in decrease allows us to conclude the existence of a more obvious convergence process. The most useful indicator is the coefficient of variation, because it allows making comparisons. The variance is computed as:

$$
\sigma^{2}=\frac{1}{n} \sum_{i=1}^{n}\left(y_{i}-\bar{y}\right)^{2}
$$

$y_{i}$ - the variable, $\mathrm{i}$ - index for spatial elements (regions, countries), $\bar{y}$ - simple arithmetic average $\left(\bar{y}=\frac{1}{n} \sum_{i=1}^{n} y_{i}\right)$

The variance expresses the degree of variation of the values compared to the average. It is affected by outliers and by the variable measurement of unit. For small samples the denominator is replaced with (n-1) instead of $n$. The variance is used to calculate the standard deviation $\left(\sigma=\sqrt{\sigma^{2}}\right)$ and the coefficient of variation $\left(C V=\frac{\sigma}{\bar{y}}\right)$, the last one expressing in a relative form the variation compared to average. According to Villaverde Castro (2004), the coefficient of variation is indicated in convergence analysis because it does not depend on the unit of measurement and the measure order of the indicators.

A decrease in time of the values for standard deviation indicates the fulfillment of convergence from the point of view of $y$ variable. This aspect is known as $\sigma$ convergence. It is recommended the use of coefficient of variation based on the population weight:

$$
C V^{\prime}=\frac{\sqrt{\sigma^{\prime 2}}}{\bar{y}}
$$

where $\sigma^{2}=\frac{1}{n} \sum_{i=1}^{n}\left(y_{i}-\bar{y}\right)^{2}\left(p_{i}-1\right), p_{i}$ - the weight of region/country population.

Analytical tools and indicators that show diminish of differences compared to average or diminish of differences between two or more time series are used to measure the convergence:

$$
\lim _{t \rightarrow \infty}(x-y)=c,
$$

The stochastic or non-stochastic principle might be used to assess the decrease of differences.

The indicator called sigma convergence is used to characterize the level of convergence by measuring the variance of GDP per capita for one year, utilizing the crosssection data about regions and countries. The indicator is relevant when comparisons are made. For describing the convergence tendency, time series are used on a discrete interval 
from $\mathrm{t}$ to $\mathrm{t}+\mathrm{T}$. In a certain time period when the variance of the variable decrease (the indicator value decrease in time), the convergence process took place: $\sigma_{t+T}<\sigma_{t}$. When the variance grows the divergence process took place: $\sigma_{t+T}>\sigma_{t}$.

The theoretical assumption that should be checked using data of a representative sample is:

$$
\frac{1}{T} \log \left(\frac{y_{i}{ }^{\prime} t_{0}+T}{y_{i} t_{0}}\right)=c-\left(\frac{1-e^{-\beta T}}{T}\right) \log \left(y_{i, t_{0}}\right)+\varepsilon^{\prime}{ }^{\prime} t_{0}, t_{0}+T,
$$

The catch up of the rich economies is confirmed by the decrease of the GDP/capita degree of variation between countries, but also by the negative sign of the annual convergence rate of the GDP/capita of countries in the sample, these countries arriving at the same time in the steady state.

\section{The sigma convergence in European Union}

The first part of this empirical application is dedicated to a spatial analysis of macroeconomic indicators in the entire Europe that includes EU-28 and only in EU-28.

The descriptive analysis is done for having a picture of the macroeconomic and population state in the entire Europe. For the GDP (thousand Euro) in Europe a map was created in GeoDa software to visualize the four groups of countries according to the GDP level (thousand Euro) in 2012.

The four groups of countries in both maps are denoted by 1 from 4 , the value 4 corresponding to the group of countries with the darkest nuance of orange.

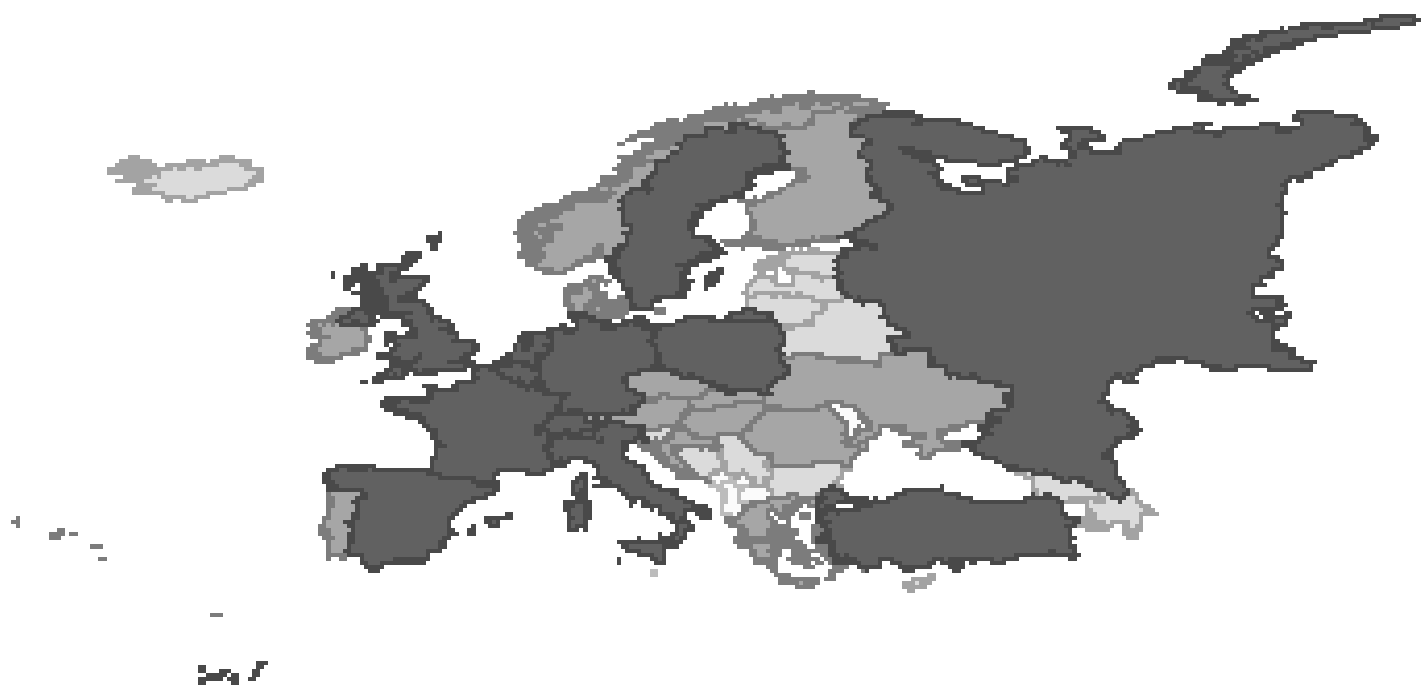

Group $1-[0 ; 8538]$

Group $2-[8578 ; 3.908 \mathrm{e}+004]$

Group $3-[4.494 \mathrm{e}+004 ; 2.726 \mathrm{e}+005]$

Group 4 - [2.896e+005; 2.356e+006]

Figure 1. Groups of countries in Europe according to GDP level in thousand Euro in 2012

Source: author's graph in GeoDa. 


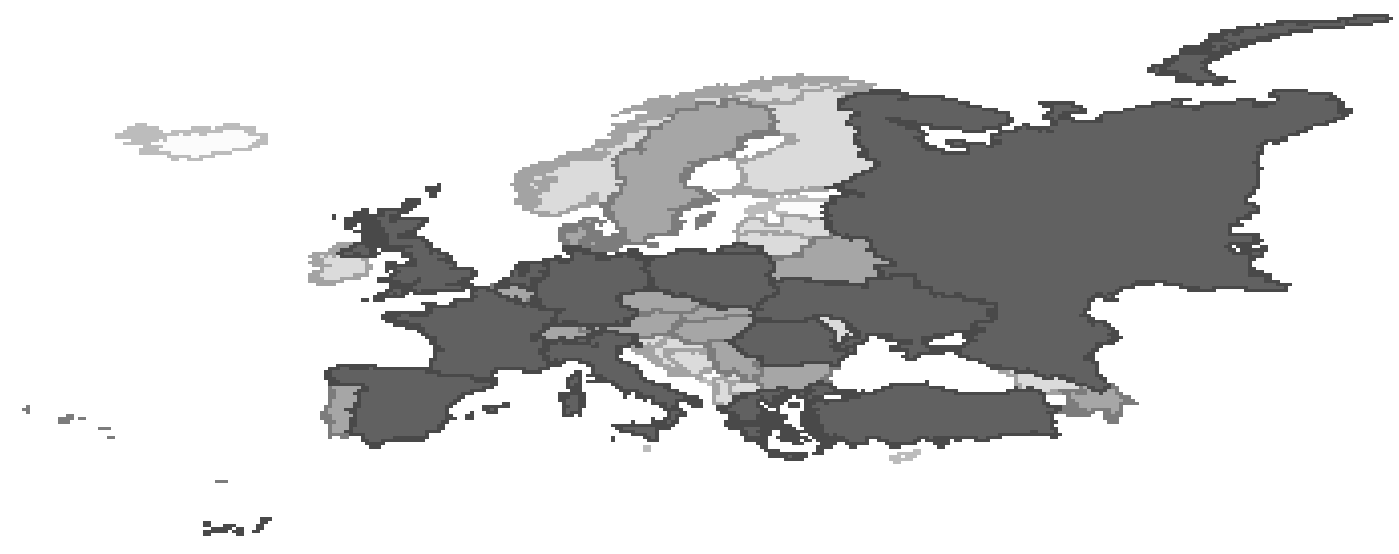

Group1 - [932; 1.337+e006]

Group $2-[2.04 \mathrm{e}+006 ; 5.354 \mathrm{e}+006]$

Group $3-[5.419 \mathrm{e}+006 ; 1.08 \mathrm{e}+007]$

Group $4-[1.132 \mathrm{e}+007 ; 1.029 \mathrm{e}+008]$

Figure 2. Groups of countries in Europe according to population in 2012

Source: author's graph in GeoDa.

The box maps are utilized to determine the outliers in a stricter way than the percentile maps. The values are grouped in 6 categories: two outlier categories and the quartiles: 1-25\%, $25-50 \%, 50-75 \%$, and $75-100 \%$. The outliers are determined using the following rule: the outliers are the values 1.5 times greater than the difference between the third percentile and the first percentile.

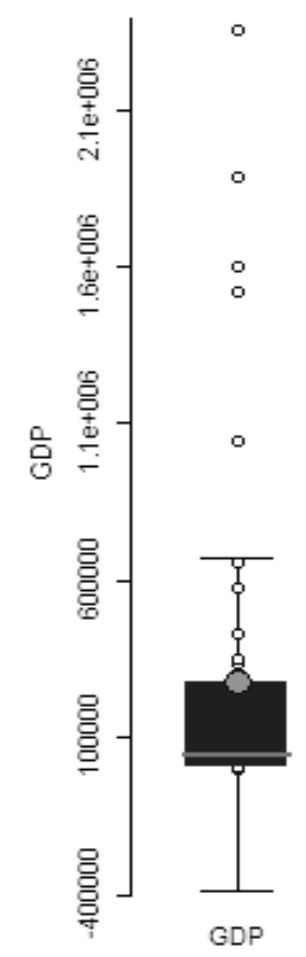

Figure 3. Box map for GDP (thousand Euro) in EU-28 in 2012

Source: author's graph in GeoDa. 
The box map for GDP (thousand Euro) shows that there is a quite high range between values. There are 5 countries with higher values than the quartiles.

A cartogram is a way to show the extreme values on a map. In this study a circular cartogram was realized in GeoDa, the countries being represented by circles. The area of each circle is proportional to the value of the chosen variable. In his case, the selected variable was GDP/capita. A nonlinear optimization routine was applied in order to place the circles close to the initial location of the matching countries. The cartogram is useful to link the actual spatial layout and the idealized layout of the observations.

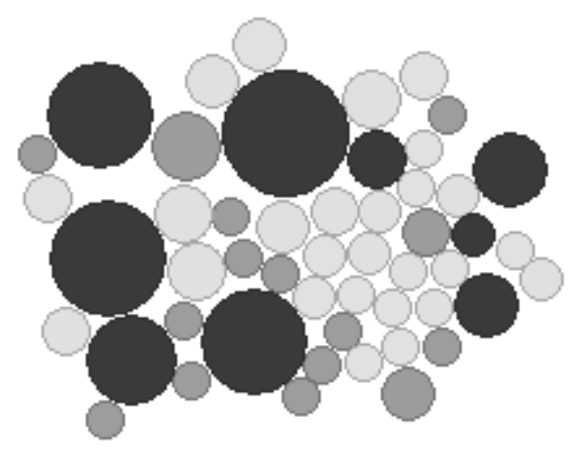

Figure 4. The cartogram of the European countries (50) according to GDP/capita in PPS Source: author's graph in GeoDa.

In this case the hinge is 1.5 . Because of the nonlinear optimization procedure, the cartogram could be improved. In this cased more 20000 iterations were used and the circles seem to jump.

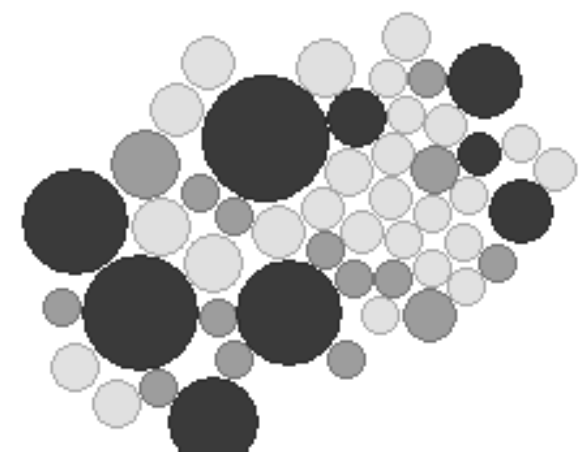

Figure 5. Improved cartogram for 20000 more iterations of the European countries (50) according to GDP/capita in PPS

Source: author's graph in GeoDa.

The parallel coordinate plot (PCP) is a good alternative to box map, the main advantage of PCP being the identification of observations that cluster in a multivariate space. The variables are seen in a multivariate comparison and they become parallel axes, on an axis the values being represented from the minimum value to the maximum value. Line segments 
are used to represent an observation with more variables. These line segments are the counterpart of the point in a multidimensional scatter plot.

Each variable was rescaled, the lowest value being on the left and the highest one on the right. The observations are ordered and located relative to the range of the values.

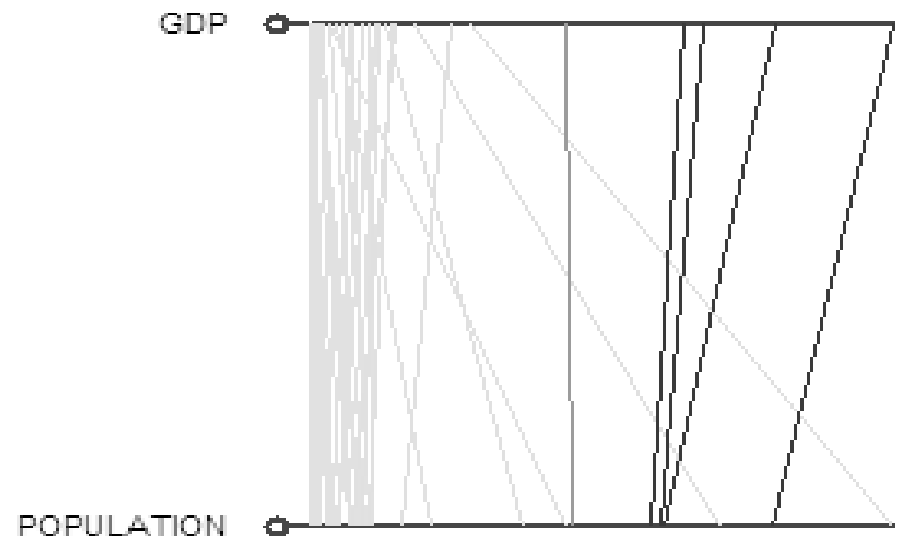

Figure 6. Parallel coordinate plot for GDP (thousand Euro) and Population in EU-28 (2012) Source: author's graph in GeoDa.

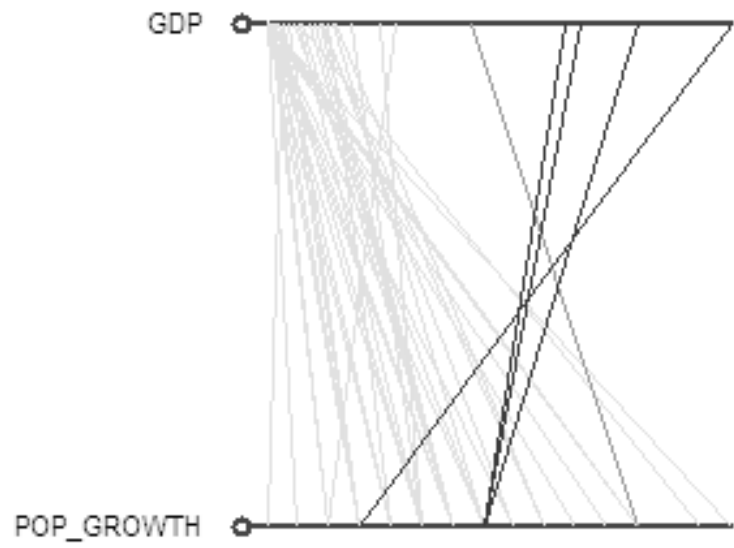

Figure 7. Parallel coordinate plot for GDP and Population growth in EU-28 (2012) Source: author's graph in GeoDa.

There are quite different PCPs if we chose GDP (thousand Euro) and population on a hand, and GDP (thousand Euro) and population growth on the other hand. Germany is the country with the highest GDP and with the largest population. The second PCP indicates that indeed Germany has the highest value of GDP (thousand Euro), but Ireland has the greatest population growth in 2012 compared to 2011.

The regression analysis was applied to determine the factor that explained better the GDP (thousand Euro) of EU-28 in 2012. Simple linear regressions were proposed, the explanatory variables being the population and the number of employed persons. The parameters of the regression models were estimated in GeoDa using ordinary least squares method and the assumptions (the auto-correlation, the homoscedasticity and the normality of errors) were checked using the proper tests. The models were valid, because the t-computed for the slope is higher than the critical value at a 5\% significance level. Moreover, the pvalues associated to the slopes are less than 0.05 . The following two graphs indicate a positive 
relationship between GDP (thousand Euro) and population, but also between GDP (thousand Euro) and employed persons.

According to Jarque-Bera test, the assumption of errors' normality is not rejected, the JB statistic being less than the critical value (5.991). However, all the applied tests for heteroscedasticity (White test, Breusch-Pagan test and Koenker-Bassett test) indicated the same results: the errors are not homoscedastic. The results of the parameters' estimations were presented in Appendix 1 for the first model and Appendix 2 for the second regression model.

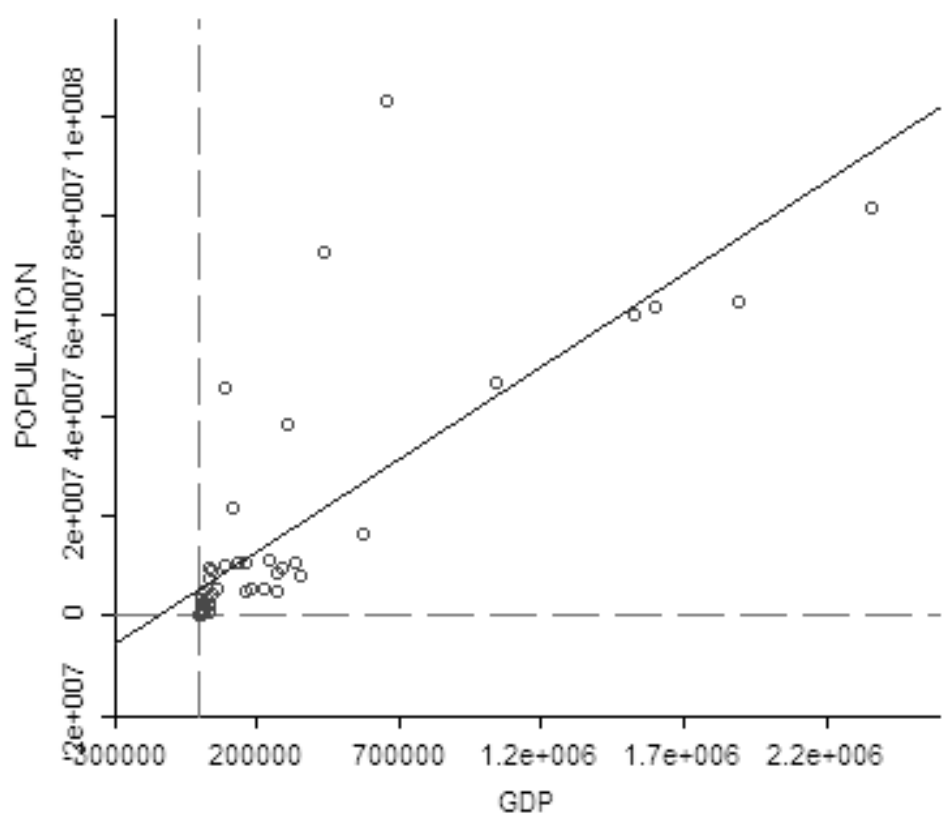

Figure 8. The relationship between GDP (thousand Euro) and population in EU-28 (2012) Source: author's graph in GeoDa.

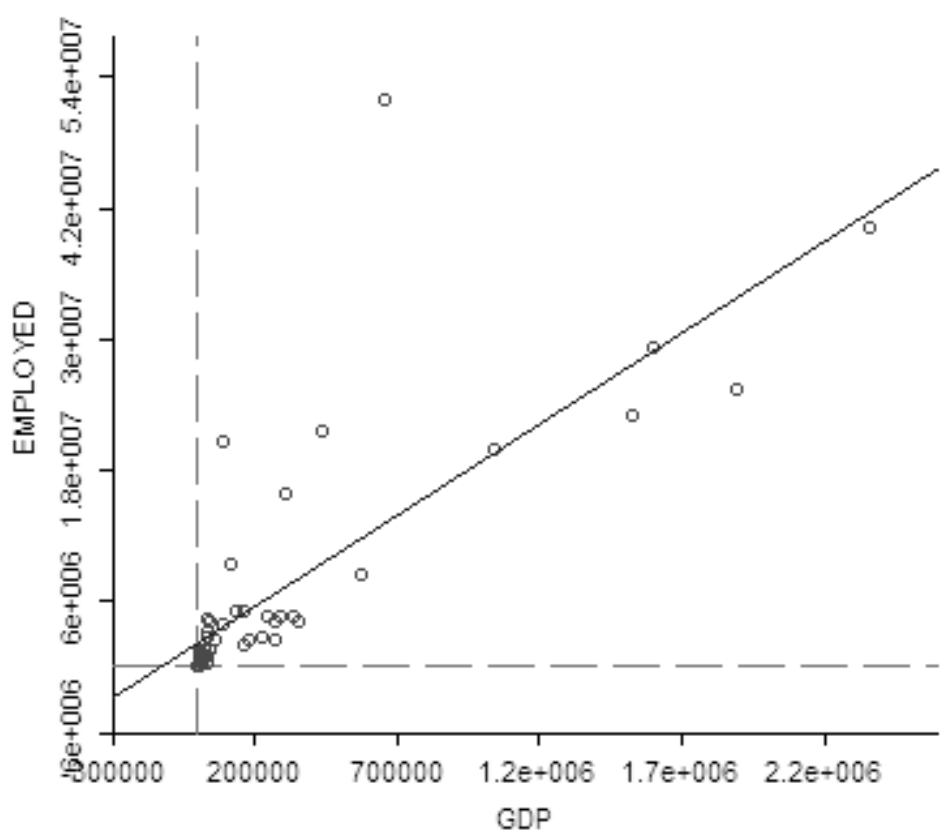

Figure 9. The relationship between GDP (thousand Euro) and employed persons in EU-28 (2012)

Source: author's graph in GeoDa. 
The two models were compared according to Akaike criterion. The differences between the values of Akaike for the two models are insignificant. However, a slightly lower value was obtained for the first model. This indicates that the populations of EU-28 countries explained better the GDP (thousand Euro) in 2012 compared to employed people.

The data referring to GDP/capita in PPS EU27=100 (volume indices of real expenditure per capita in PPS EU27=100) for 2000 and 2012 are provided by Eurostat. The dataset was expressed as ratios relative to the EU average in 2000 and 2012. The variance and the standard deviation were computed for EU-27 and EU-28 in 2000 and 2012. The results of the computations are presented in Table 1 .

Table 1. Measures of variability for GDP/capita in PPS (EU27=100) in EU27 and EU28

\begin{tabular}{ccccc}
\hline Region & Year & Variance & $\begin{array}{c}\text { Standard } \\
\text { deviation }\end{array}$ & $\begin{array}{c}\text { Coefficient of } \\
\text { variation (\%) }\end{array}$ \\
\hline EU-28 & 2000 & 0.2342 & 0.4839 & $48.39 \%$ \\
\hline EU-28 & 2012 & 0.1766 & 0.4203 & $42.03 \%$ \\
\hline EU-27 & 2000 & 0.2203 & 0.4694 & $46.94 \%$ \\
\hline EU-27 & 2012 & 0.1746 & 0.4178 & $41.78 \%$ \\
\hline
\end{tabular}

Source: author's computations.

The reason for making the comparison between EU-27 and EU-28 is related to the fact that the previous studies did not take into account the convergence in EU-28 and we might be interested to see that the adding of a country generates a progress in convergence process. It is important here to check if the new member of EU had a good contribution to the realization of convergence process or a negative influence by the accentuation of the divergence.

In both years (2000 and 2012) the dataset for GDP/capita in PPS EU27 is heterogeneous, the coefficient of variation being greater than the threshold of $30-35 \%$. However, in 2012 in both regions (EU27 and EU28) the coefficient of variation decreased from $46.94 \%$ to $41.78 \%$, respectively from $48.39 \%$ to $42.03 \%$. Therefore, the conclusion would be that in the analyzed period the degree of variation decreased and even if the economic convergence is not confirmed by the variability measures some improvements were made in this direction.

The other method with EU27 and EU28 populations' weights is used. The weights are determined as the population of each country over the overall population of the EU in 2000 , respectively 2012.

Table 2. Measures of variability for GDP/capita in PPS (EU27=100) in EU27 and EU28 using populations' weights

\begin{tabular}{ccccc}
\hline Region & Year & Variance & $\begin{array}{c}\text { Standard } \\
\text { deviation }\end{array}$ & $\begin{array}{c}\text { Coefficient of } \\
\text { variation (\%) }\end{array}$ \\
\hline EU-28 & 2000 & 0.2134 & 0.4619 & $44.45 \%$ \\
\hline EU-28 & 2012 & 0.1684 & 0.4104 & $40.35 \%$ \\
\hline EU-27 & 2000 & 0.2178 & 0.4666 & $44.53 \%$ \\
\hline EU-27 & 2012 & 0.1662 & 0.4077 & $40.37 \%$ \\
\hline
\end{tabular}

Source: author's computations.

The variability measures indicate that there was an obvious decrease of the indicators in 2012 compared to 2000 in both regions (EU27 and EU28). This implies that the weighted 
method suggested an improvement in the achievement of this convergence criterion. However, the indicators' values still show a slow degree of convergence. In EU28 the coefficient of variation is lower than the value registered for EU27, but the difference is almost insignificant. The coefficient of variation could be used to make comparisons with the results of the previous method. Lower values were obtained for the weighted method that indicates a better degree of convergence in EU.

Table 3. Variability indicators for real expenditure in PPS of EU28 (purchasing power parity in EU28) during 2000-2012

\begin{tabular}{cccc}
\hline Region & Variance & $\begin{array}{c}\text { Standard } \\
\text { deviation }\end{array}$ & $\begin{array}{c}\text { Coefficient of } \\
\text { variation }\end{array}$ \\
\hline EU-28 & 0.001111 & 0.033337 & $3.3356 \%$ \\
\hline EU-27 & 0.001114 & 0.033378 & $3.3397 \%$ \\
\hline
\end{tabular}

Source: author's computations.

The results in dynamics for real expenditure in PPS indicate that during 2000-2012 a slow degree of variability in GDP per capita in PPS for EU28 purchasing power parity was registered with a minor decrease for EU-28 compared to EU-27.

\section{Conclusions}

The sigma convergence was assessed in this study for European Union using statistical variation measures. Therefore, standard deviation and coefficient of variation for GDP/capita in PPS were computed in two versions: the standard version and the variant that takes into account population's weight.

During 2000-2012 the degree of variation decreased, but the economic convergence is not confirmed, the coefficient of variation being more than $40 \%$ for both methods. However, the weighted method suggested an improvement in the achievement of this convergence criterion

The analysis in dynamics of the real expenditure in PPS showed that during 20002012 a slow degree of variability in GDP per capita in PPS for EU28 purchasing power was observed.

All in all, it is important to measure the achievement of the sigma criterion of convergence in time to get the proper decisions for improve the degree of convergence. This study for EU-28 is relevant, by taking into account the situation of the new EU memberCroatia. The research might be developed by assessing the other indicators that could be a good hint for showing the degree of convergence process.

\section{References}

Albu, L. L. \& Roudoi, A. (2003), Scenarios Of Economic Development In Romania Medium To Long-Term Forecasting Models, Journal for Economic Forecasting, Institute for Economic Forecasting, Vol. 0(5), December, pp. 64-77.

Azomahou, T.T., El ouardighi, J., Nguyen-Van, P., Cuong Pham, T.K. (2011), Testing convergence of European regions: A semiparametric approach, Economic Modelling, Vol. 28, Issue 3, May 2011, pp. 1202-1210.

Beyaert, C., García-Solanes, M. (2014), Output gap and non-linear economic convergence, Journal of Policy Modeling, Vol. 36, Issue 1, January-February 2014, pp. 121-135. 
Caraiani, P. (2010), Forecasting Romanian GDP Using a BVAR Model, Journal for Economic Forecasting, Institute for Economic Forecasting, Vol. 0(4), December, pp. 76-87.

Crespo-Cuaresma, J., Fernández-Amador, F. (2013), Business cycle convergence in EMU: A first look at the second moment, Journal of Macroeconomics, Vol. 37, September 2013, pp. 265-284.

Cuaresma, J.C., Havettová, M., Lábaj, M. (2013), Income convergence prospects in Europe: Assessing the role of human capital dynamics, Economic Systems, Vol. 37, Issue 4, December 2013, pp. 493-507.

Kutan, A.M., Yigit, T.M. (2009), European integration, productivity growth and real convergence: Evidence from the new member states, Economic Systems, Vol. 33, Issue 2, June 2009, pp. 127-137.

Iancu, A. (2009), Real Economic Convergence, Working Papers of National Institute of Economic Research 090104, National Institute of Economic Research.

Lavrinenko, O., Lavrinovich, I., Ohotina, A. (2014), Factors of income differention in Latvia: 2000-2011, ActualProblems of Economics, No. 3(153), pp. 359-369.

Le Pen, Y. (2011), A pair-wise approach to output convergence between European regions, Economic Modelling, Vol. 28, Issue 3, May 2011, pp. 955-964.

Mihut, I. S., Lutas M. (2013), Testing Sigma convergence across new EU members, Revista Economică, Vol. 65, No. 2-6.

Monfort, M., Cuestas, J.C., Ordóñez, J. (2013), Real convergence in Europe: A cluster analysis, Economic Modelling, Vol. 33, July 2013, pp. 689-694.

Palan, N., Schmiedeberg, C. (2010), Structural Change and Economic Dynamics, Vol. 21, Issue 2, May 2010, pp. 85-100.

Villaverde Castro, J. (2004), Indicators of real economic convergence, A. Primer, UNU CRISE, Working papers, W-2004/2. 
Appendix 1 population

The parameters' estimation of the regression for GDP (thousands Euro) and

Dependent Variable: GDP Number of Observations: 28

Mean dependent var: 275334 Number of Variables: 2

S.D. dependent var: 510963 Degrees of Freedom: 26

R-squared: 0,614364 F-statistic: 76,4698

Adjusted R-squared: 0,606330 Prob(F-statistic): 1,68966e-011

Sum squared residual: 5,03415e+012 Log likelihood: $-704,328$

Sigma-square: 1,04878e+011 Akaike info criterion: 1412,66

S.E. of regression: 323849 Schwarz criterion: 1416,48

Sigma-square ML: 1,00683e+011

S.E of regression ML: 317306

Variable Coefficient Std.Error t-Statistic Probability

$\begin{array}{lllll}\text { CONSTANT } \quad 16130,65 & 54554,25 & 0,2956809 & 0,7687508\end{array}$

POPULATION $0,01651297 \quad 0,001888348,744703 \quad 0,0000000$

Regression diagnostics

Test on normality of errors

$\begin{array}{lccc}\text { TEST } & \text { DF } & \text { VALUE } & \text { PROB } \\ \text { Jarque-Bera } & 2 & 3,08874 & 0,2333\end{array}$

Diagnostics for heteroskedasticity

Random coefficients

$\begin{array}{lccl}\text { TEST } & \text { DF } & \text { VALUE } & \text { PROB } \\ \text { Breusch-Pagan test } & 1 & 135,7362 & 0,0000000 \\ \text { Koenker-Bassett test } & 1 & 45,8487 & 0,0000000\end{array}$

Specification robust test

$\begin{array}{llrl}\text { TEST } & \text { DF } & \text { VALUE } & \text { PROB } \\ \text { White } & 2 & 45,86552 & 0,0000000\end{array}$

Coefficients variance matrix

CONSTANT POPULATION

$2976166296,920625-55,972713$

$-55,972713 \quad 0,000004$ 


\section{Appendix 2} persons

The parameters' estimation of the regression for GDP (thousands Euro) and employed

Dependent Variable: GDP Number of Observations: 28

Mean dependent var: 275334 Number of Variables: 2

S.D. dependent var: 510963 Degrees of Freedom: 26

R-squared: 0,613052 F-statistic: 76,0477

Adjusted R-squared: 0,604991 Prob(F-statistic): 1,83504e-011

Sum squared residual: 5,05129e+012 Log likelihood: $-704,413$

Sigma-square: 1,05235e+011 Akaike info criterion: 1412,83

S.E. of regression: 324400 Schwarz criterion: 1416,65

Sigma-square ML: 1,01026e+011

S.E of regression ML: 317845

Variable Coefficient Std.Error t-Statistic Probability

$\begin{array}{lcccc}\text { CONSTANT } & 24951,84 & 54120,9 & 0,4610388 & 0,6468540 \\ \text { EMPLOYED } & 0,03660081 & 0,004197084 & 8,720532 & 0,0000000\end{array}$

Regression diagnostics

Test on normality of errors

$\begin{array}{lccl}\text { TEST } & \text { DF } & \text { VALUE } & \text { PROB } \\ \text { Jarque-Bera } & 2 & 2,71352 & 0,317\end{array}$

Diagnostics for heteroskedasticity

Random coefficients

\begin{tabular}{|c|c|c|c|}
\hline \multirow{2}{*}{\multicolumn{2}{|c|}{$\begin{array}{l}\text { TEST } \\
\text { Breusch-Pagan test } 1\end{array}$}} & VALUE & PROB \\
\hline & & 169,7329 & 0,0000000 \\
\hline \multicolumn{4}{|c|}{ Koenker-Bassett test 1} \\
\hline \multicolumn{4}{|c|}{ Specification robust test } \\
\hline TEST & DF & VALUE & PROB \\
\hline White & 2 & 44,15854 & 0,0000000 \\
\hline
\end{tabular}

COEFFICIENTS VARIANCE MATRIX

CONSTANT EMPLOYED

2929072143,367480 -120,506029

$-120,5060290,000018$ 